\title{
Development of Geospatial Information System Database for Banking Facilities within Gusau Metropolis, Zamfara State, Nigeria.
}

\author{
Sule J. O ${ }^{1}$, Dr. Musa A. A ${ }^{2}$. and Abubakar B. M. ${ }^{3}$ \\ ${ }^{1,3}$ Department of Geomatics, Faculty of Environmental Design, A.B.U, Zaria \\ ${ }^{2}$ Department of Surveying and Geoinformatics, F.U.T., Yola.
}

\begin{abstract}
The technological development and progress of geographical world is taking place in a very fast pace. This necessitates having a system capable of manipulating spatial and non-spatial data in digital form and giving the output in short time. GIS can be used by companies to site new locations to take advantage of previously underserved market. In recent years, the banking industry has been undergoing drastic changes, reflecting a number of underlying developments. Significant advancements in communication and information technology accelerated and broadened the dissemination of financial information and financial services and also increased the complexity. Another key impetus for change has been the increasing competition among a broad range of domestic and foreign institutions in providing banking and related financial services. Regulations are forcing the banks to adopt better operational strategies and upgrade their skills. All these factors throw more challenges to banking sector. Unfortunately, the distribution of these facilities in Gusau metropolis is quite uneven, which make customer waste time and fuel in getting access to such facilities. IKONOS satellite imagery (1m resolution) was geo-referenced and digitized showing the location of each and every banking facility in the study area. The geo-database was created using Ms Excel 2007, and ArcGIS 9.3 software. The database was queried and the results were analyzed. The results showed the locations of these facilities and how secured they are, by relating their distribution with that of the security agencies.
\end{abstract}

Keywords: IKONOS Satellite Imagery, ArcGIS 9.3 software, Georeference, Digitize, layout, Banking, Geodatabase.

\section{Introduction}

Surveying is a science that deals with determining the relative position of points on or near the earth's surface. These points may be needed for construction to locate or layout roads, airfields and structures of all kind or for cultural, hydrographical, or terrain features for mapping. The earliest application of surveying was for establishing land boundaries. Surveying has also branched out to many fields that parallel the advancement of civil engineering and civilization. Surveyors may be called upon to appear in court to substantiate definite locations of various objects, such as those involved in major traffic accidents, maritime disasters, or even murder cases [1].

Geographic Information System (GIS) is an evolving, catchall phrase that initially referred to the management of information with a geographic component primarily stored in vector form with associated attributes. This definition quickly became too restrictive with advances in software and ideas about information management [2]. An advanced GIS system should be able to handle any spatial data, not just data tied to the ground by geographic reference points. The capacity to handle non-geographic spatial data was formerly the domain of the systems referred to as AM/FM (Automated Mapping / Facilities Management). Other nongeographic applications, such as interactive medical encyclopaedias that retrieve information based on the human form, should also be manageable by a robust system [3].

Zamfara State was created in 1996 with Gusau as the capital town. Within the former structure of Sokoto State, Gusau is the largest town in population size. Lafia metropolis stretches between latitudes $06^{\circ} 37^{\prime}$ $00^{\prime \prime}-06^{\circ} 43^{\prime} 00^{\prime \prime}$ and between longitude $12^{\circ} 08^{\prime} 30^{\prime \prime}-12^{\circ} 12^{\prime} 30^{\prime \prime}$. Figure 1 , below is the satellite imagery for Gusau metropolis. 


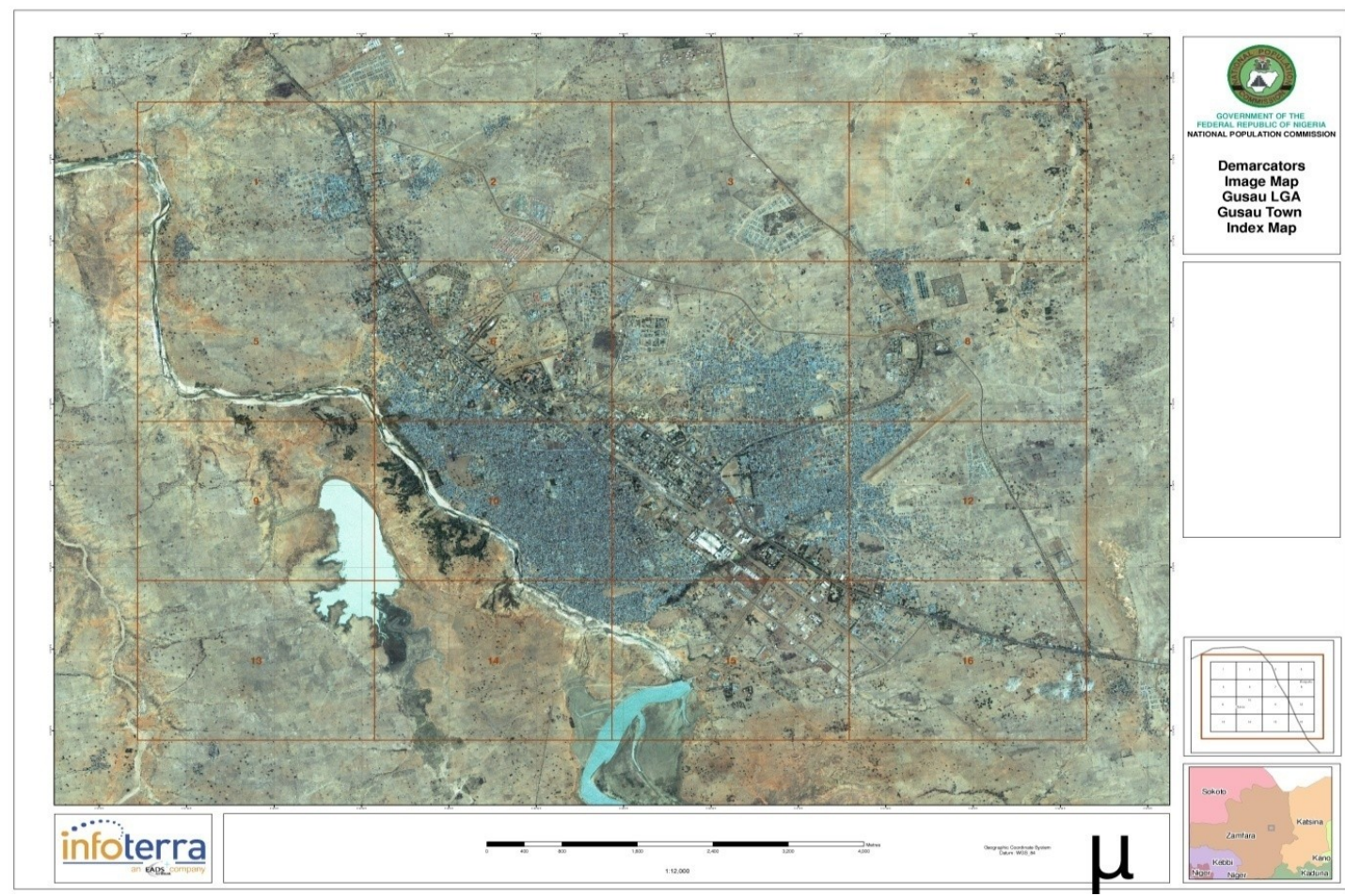

Figure 1: Image of Gusau District (NPC, 2009).

Developing GIS Tools to Integrate MCDMS Models for the Analysis of Bank Branch Closure has been reported [4]. In the research, MCDMS (Multi Criteria Decision Making Systems) methods have been integrated with a GIS to provide the means to prioritize branch closure procedures based upon a variety of different choice criteria and on the importance (weight) a decision maker might attach to these. The approach represents the methodology for the development of effective spatial decision support environment (SDSS) for branch bank rationalization by integrating MCDMS and GIS [5]. This decision making environment is designed to enable the decision maker to evaluate the applicability of the procedures and techniques in order to generate decision making scenarios and finally implement the decision process by re-evaluating different scenarios based on his/her own familiar concept and knowledge. This research primarily focuses on the methodology for developing a GIS-based Multi-Criteria Decision Making system (GIS-MCDMS) for application in the retail banking environment, rather than on the development of entirely new software to address this task.

Lack of comprehensive Geospatial Information system and database contribute to problems for individuals, government agencies and other organisations that frequently patronize the banking sector. The major problem is the waste of time and fuel by customers in visiting the banks in spaghetti fashion. Also, the inability to get accurate distances between banks is another problem. Also, lack of even distribution of ATM machines within the metropolis is another problem costumer encounter daily. The primary aim of this work is to develop a comprehensive GIS database for banking facilities in Gusau metropolis.

\subsection{Map Making in GIS}

GIS map making should transcend traditional cartography—roads, streams, and political boundaries along with map grids, scale bars, and legends may be sufficient for some maps but are not an adequate reflection of a fully featured GIS system. You should be able to incorporate a satellite or air photo image as the background for line and polygon data with transparent polygon filling to reveal the background through vector or CAD overlays. You should be able to incorporate enlarged insets and elements that tie the components at both map scales together [6].

\subsection{Geographic Information System}

Geographic information systems (GIS) or geospatial information systems is a set of tools that captures, stores, analyses, manages, and presents data that are linked to location(s). In the simplest terms, GIS is the merging of cartography, statistical analysis, and database technology. GIS systems are used in cartography, remote sensing, land surveying, public utility management, natural resource management, photogrammetry, geography, urban planning, emergency management, navigation, aerial video, and localized search engines [7]. 


\subsection{Data for GIS applications}

Data for GIS applications includes; digitised and scanned data, databases, GPS field sampling of attributes and remote sensing and aerial photography.

\subsection{GIS Techniques and Technology}

Modern GIS technologies use digital information, for which various digitized data creation method are used. The most common method of data creation is digitization, where a hard copy map or survey plan is transferred into a digital medium through the use of a computer-aided design (CAD) program, and georeferencing capabilities. With the wide availability of ortho-rectified imagery (both from satellite and aerial sources), heads-up digitizing is becoming the main avenue through which geographic data is extracted. Headsup digitizing involves the tracing of geographic data directly on top of the aerial imagery instead of by the traditional method of tracing the geographic form on a separate digitizing tablet (heads-down digitizing) [8].

\subsection{Data Used}

\section{Methodology}

The following were the data used; IKONOS satellite image ( $1 \mathrm{~m}$ resolution), list of banks operating within Gusau metropolis and GPS receiver data.

\subsection{Hardware}

The following are the hardware used; an HP laptop Computer system, an HP LaserJet Printer and Garmin 12XL Handheld GPS receiver

\subsection{Software}

The following are software used; Esri ArcGIS9.2 (used for carrying out this work), Geocalc (used for coordinates transformation) and Microsoft office (used for typing of the project).

\subsection{Field Work}

The execution of this research involves some fieldwork. This Include:

i. GPS Recordings: All the banks in Gusau metropolis were coordinated using handheld GPS (GARMIN 12XL). The GPS has accuracy of 5 to 10 meters depending on the satellite available and the geometry of those satellites at any point in time.

ii. Enquiry of data about each bank through distribution and collection of Questionnaires.

\subsection{Geo-referencing}

Four points UTM coordinates were used to geo-reference the satellite image obtained.

Procedures for geo-referencing a Map include the following steps;

$>$ Add the raster dataset you want to geo-reference.

$>$ Click on geo-referencing toolbar and click on Fit to Display.

$>$ Click on Control Point tool to add control point.

$>$ To add the control points, click the mouse pointer on a known location on the raster dataset, then right click and left click, and input $\mathrm{X}$ and $\mathrm{Y}$ coordinates values of that point.

$>$ After adding the four control points, you can examine the residual error for each link and the Total RMS error by clicking on the View Link Table tool. If satisfied with the registration, then stop registering links.

$>$ Click on Georeferencing toolbar and click Update Georeferencing to save the transformation information with the raster dataset.

\subsection{Digitising}

(i) Shape files for various layers were created using ArcCatalog so that they can be edited after it is dragged to the ArcMap.

(ii) Then ArcMap was launched and the saved layers (shape files created) were dragged from ArcCatalog to ArcMap so that they can be seen in the list items. The shape files for layers and other data exported were also created. When this is completed a colour is assigned to the layer.

\subsection{Plotting of Coordinates on the Base Map}

The coordinates of each is typed in Microsoft excel and saved as word 97-2003 document so that it can be plotted in the ArcMap environment. The table containing the $\mathrm{x}, \mathrm{y}$ coordinates can be added to the map in ArcMap through the following steps;

$>$ Click the Tools menu on the standard toolbar and click Add XY Data.

$>$ Click the table dropdown arrow and click on a table containing the $\mathrm{x}, \mathrm{y}$ coordinate data. 
$>$ Click the X Field dropdown arrow and click the containing X-coordinate values.

$>$ Click the Y Field dropdown arrow and click the field containing y-coordinate values.

$>$ Click on Edit to define the coordinate system and units represented in the $\mathrm{x}$ and $\mathrm{y}$ fields.

$>$ The X,Y coordinate automatically transforms to the coordinate system of the data frame 2.8 Adding Data in ARCMAP

The following procedures were adopted;

- Launch ArcMap

- Click the "add data" button on the standard toolbar

- Click the "look in" drop down arrow and navigate to the folder that contains the data source.

- $\quad$ Click the data source and click add.

ArcMap creates a new layer on the map that regenerates the data source.

\subsection{Adding Data to Attribute Table in ARCMAP}

The procedures adopted were as follows;

- Launch ArcMap

- Right click the layer and click "open attribute table"

- Click on option and click "add field"

- A dialog box appears on the screen. Enter the name (data) and then click OK.

- Click on "start editing"

- Enter data in the field created

- Click "stop editing"

\subsection{Query Building}

Performing queries on GIS database is an essential part of most GIS projects. Queries offer methods of data retrieval, and can be performed on data that are part of GIS database, or new data produced as a result of data analysis. Queries are useful at all stages of GIS analysis for checking the quality of data and results obtained. The query was carried out using the query builder. This was carried out as follows

i. The query builder tool is accessed by clicking on 'selection' on the menu bar and the dialog box appears, 'select by Attributes' is clicked on.

ii. The query expression is built by either typing it in or clicking on the required fields, operators and values in the dialog box.

Query 1: Highlight of banks

Query format:

$>$ SELECT*FROM ALL_FEATURES_Merge WHERE:

"TYPE" = 'BANK' (see figure 3 and 4)

Query 2: Highlight of security agencies

Query format:

> SELECT*FROM ALL_FEATURES_Merge WHERE:

"TYPE" = 'SECURITY AGENCIES'

(see figure 5 and 6)

Query 3: Highlight of ATM machines

Query format:

$>$ SELECT*FROM ALL_FEATURES_Merge WHERE:

"TYPE" = 'ATM MACHINE' - (see figure 10 and 11) 


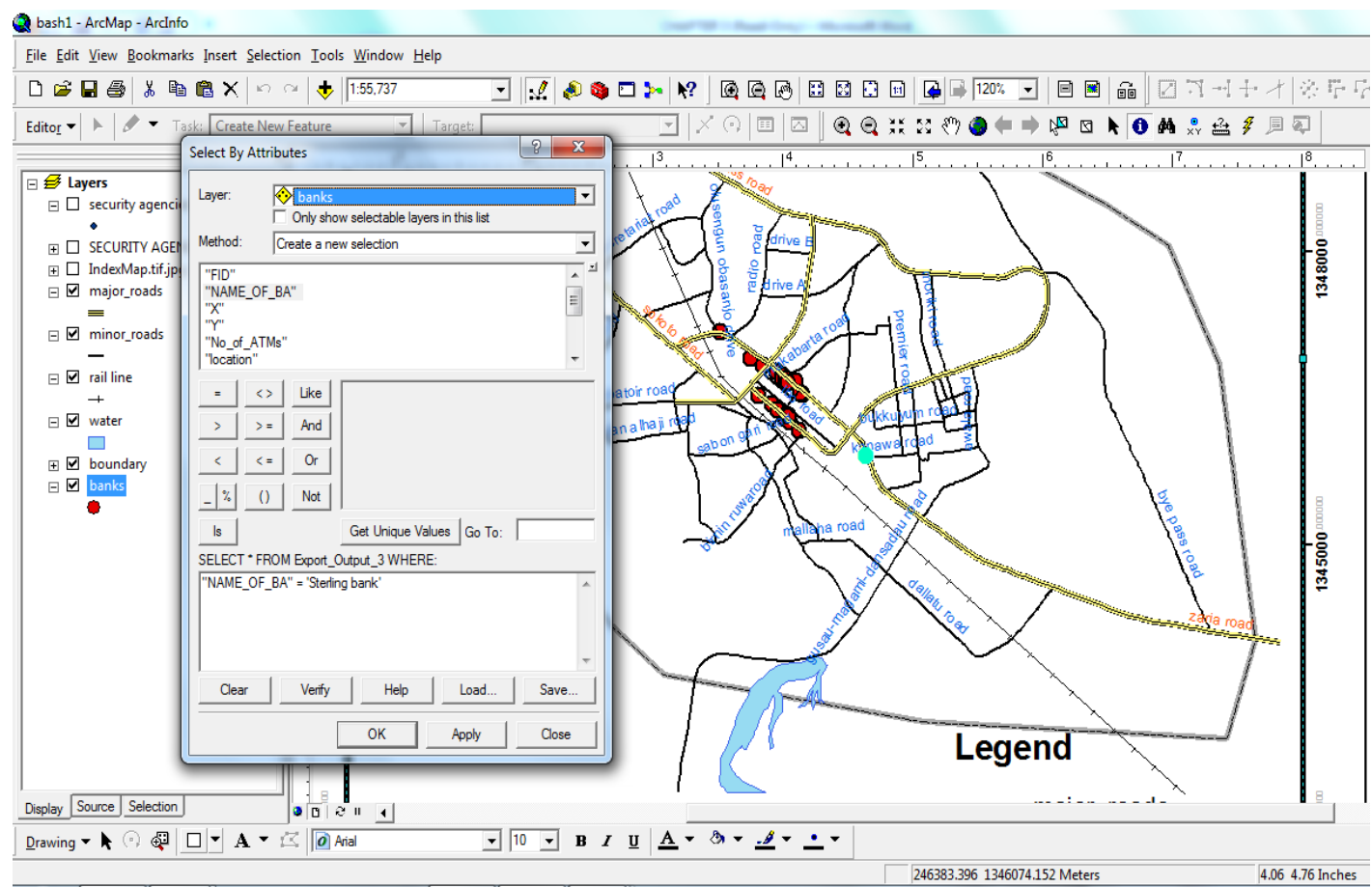

Figure 2: Display of typical query format in ArcGIS 9.2

\subsection{Output and Prints}

After map composition, from the view menu a layout was created and grid lines generated over the area extent. A layout makes it easy to produce quality maps with arcGIS9.2. with a layout one can assemble all the components needed to appear on a map arranged together to get a desirable output and then print out when needed.

\subsection{Results}

\section{Results and Analysis}

The figures 3 - 11 display the distribution and location of banks, ATM machines, security agencies and road network within Gusau metropolis respectively. The results can help in decision making concerning the banking sector.

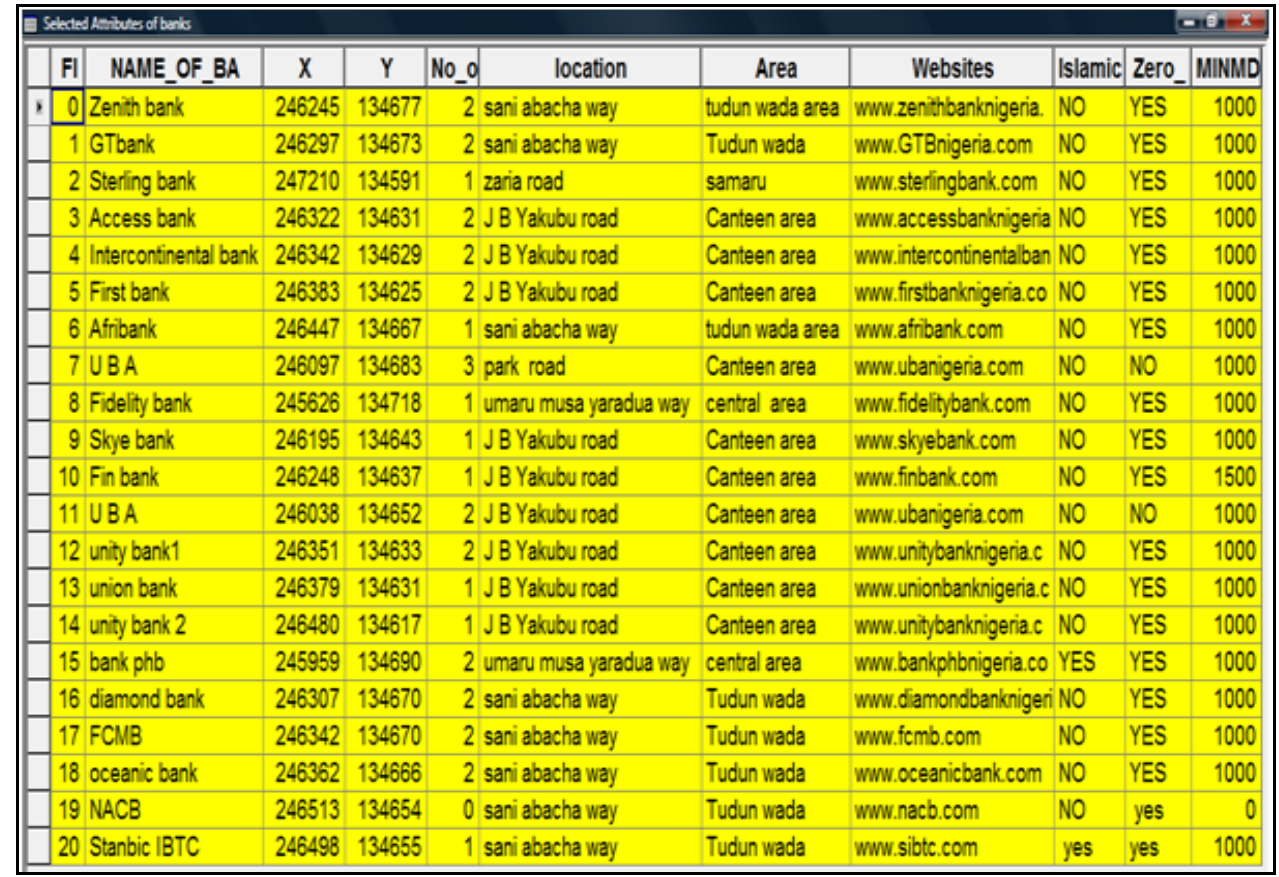

Figure 3: Attributes table of banks 


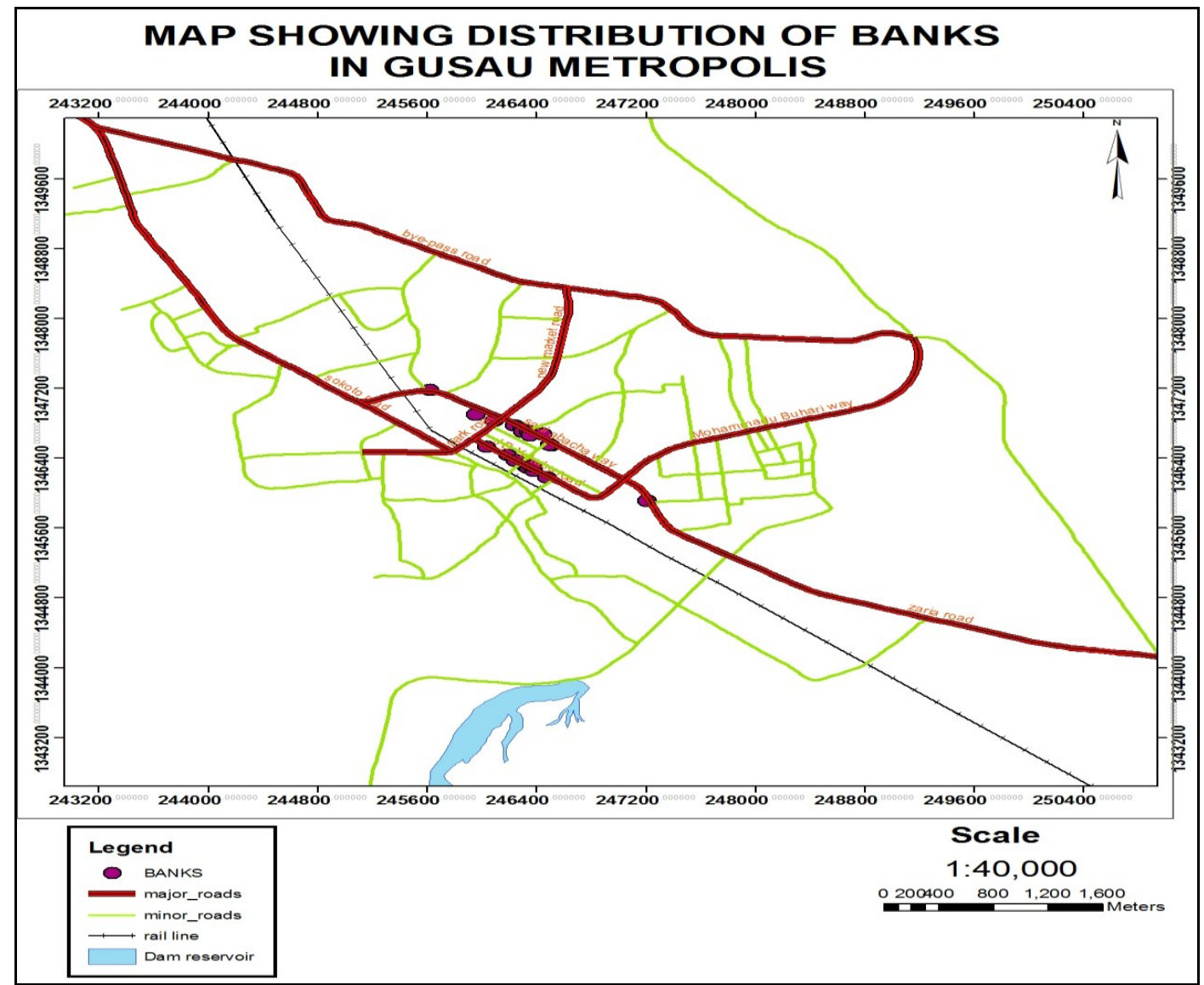

Figure 4: Distribution of banks within Gusau metropolis

\begin{tabular}{||l|c|l|l|l|l|}
\hline \multicolumn{1}{|c|}{ name } & X & \multicolumn{1}{c|}{ Y } & \multicolumn{1}{c|}{ location } & \multicolumn{1}{c|}{ district } & \multicolumn{1}{c|}{ Shape * } \\
\hline , & 246082 & 1346772 police road & canteen area & Point \\
\hline central poice station & 246014 & 1346838 umaru musa yaradua way & central area & Point \\
\hline tudun wada police station & 247407 & 1346230 bukkuyum road & tudun wada & Point \\
\hline state fire service & 247861 & 1345218 zaria road & samaru area & Point \\
\hline central market fire service & 246094 & 1347616 radio road & central area & Point \\
\hline zamfara police command headquaters & 248683 & 1348397 kaura namoda road & unguwar gwaza & Point \\
\hline mortgage police station & 246499 & 1345321 mortgage road & mortgage area & Point \\
\hline zamfara mobile police command & 250648 & 1344903 bye pass 2 road & bye pass & Point \\
\hline
\end{tabular}

Figure 5: Attributes table of security agencies within Gusau metropolis 


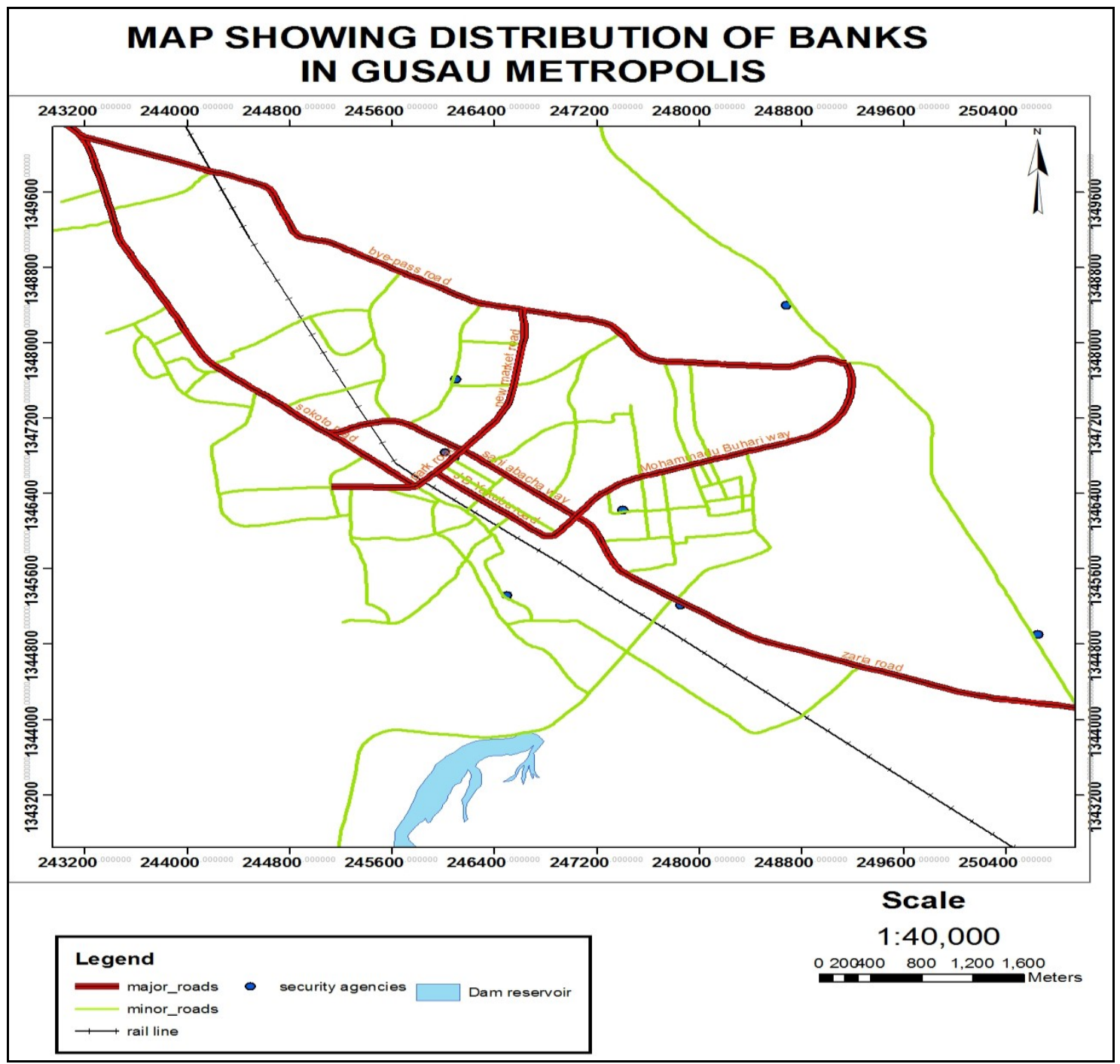

Figure 6: Distribution of security agencies within Gusau metropolis

\begin{tabular}{|c|c|c|c|c|c|}
\hline & FI & Shap & Id & name & location \\
\hline & 0 & Polyli & o & umaru musa yaradua way & central area \\
\hline & 1 & Polyli & o & zaria road & samaru area \\
\hline & 2 & Polyli & o & sani abacha way & tudun wada area \\
\hline & 3 & Polyli & o & J B Yakubu road & canteen area \\
\hline * & 4 & Polyli & o & park road & canteen \\
\hline & 5 & Polyli & o & sokoto road & G R A \\
\hline & 6 & Polyli & o & old market road & kofar jange \\
\hline & 7 & Polyli & o & Mohammadu Buhari way & tudun wada \\
\hline & 9 & Polyli & o & new market road & ungurvar dallatu \\
\hline & 8 & Polyli & o & bye-pass road & janyau \\
\hline & & & & & \\
\hline
\end{tabular}

Figure 7: Attributes of major roads in Gusau metropolis 
Development of Geospatial Information System Database for Banking Facilities Within....

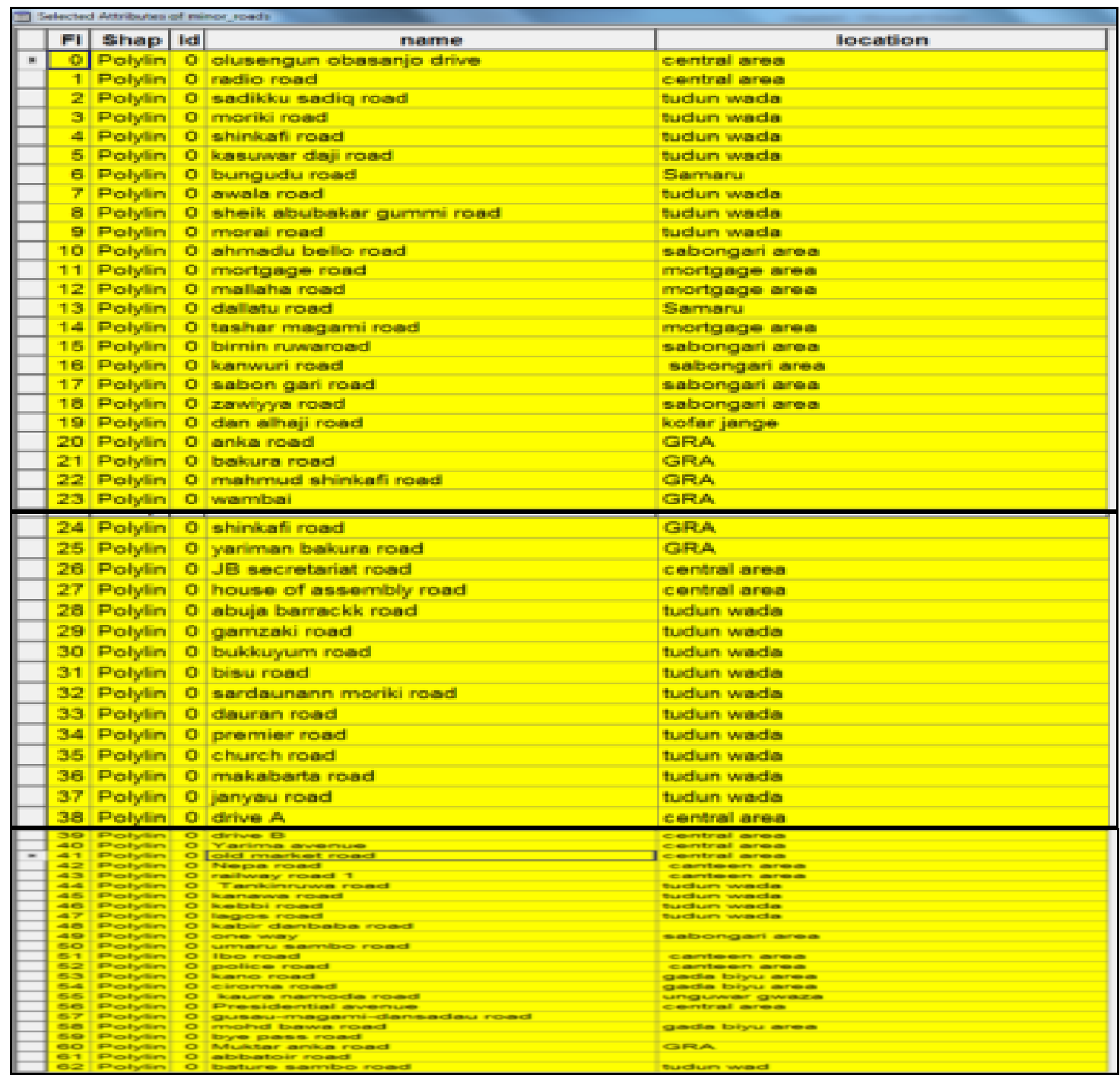

Figure 8: Attributes of minor roads within Gusau metropolis 


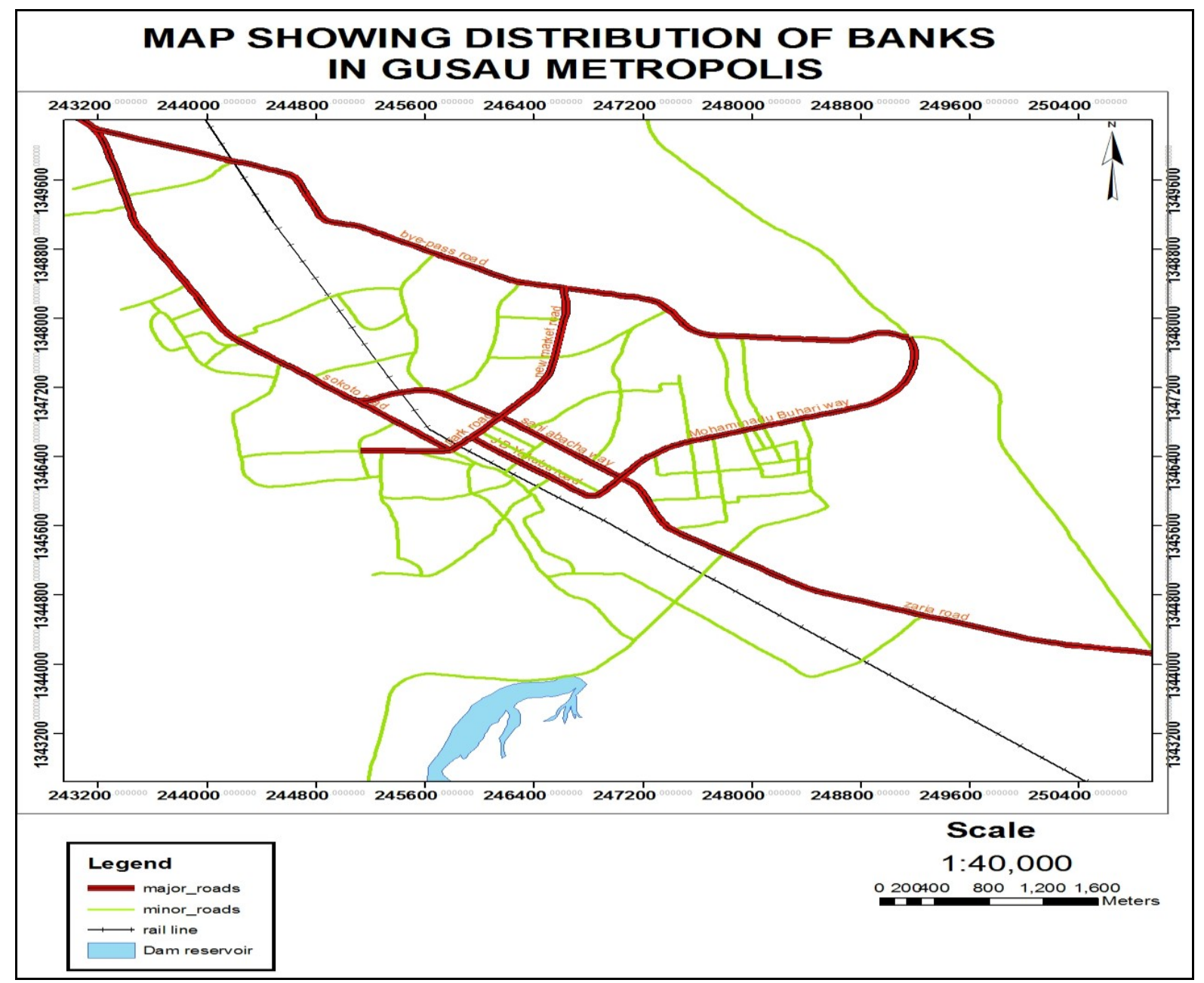

Figure 9: Map showing road network within Gusau metropolis

\begin{tabular}{|c|c|c|c|c|c|c|c|c|}
\hline & $\mathbf{F I}$ & Shap & NAME_OF_BA & $\mathbf{x}$ & $\mathbf{Y}$ & No_of_ATMs & location & Area \\
\hline & 0 & Point & Zenith bank & 246245 & 134677 & 2 & sani abacha way & tudun wada area \\
\hline & 1 & Point & GTbank & 246297 & 134673 & 2 & sani abacha way & Tudun wada \\
\hline & 2 & Point & Sterling bank & 247210 & 134591 & 1 & zaria road & samaru \\
\hline & 3 & Point & Access bank & 246322 & 134631 & 2 & J B Yakubu road & Canteen area \\
\hline & 4 & Point & Intercontinental bank & 246342 & 134629 & 2 & J B Yakubu road & Canteen area \\
\hline & 5 & Point & First bank & 246383 & 134625 & 2 & J B Yakubu road & Canteen area \\
\hline & 6 & Point & Afribank & 246447 & 134667 & 1 & sani abacha way & tudun wada area \\
\hline & 7 & Point & U B A & 246097 & 134683 & 3 & park road & Canteen area \\
\hline & 8 & Point & Fidelity bank & 245626 & 134718 & 1 & umaru musa yaradua way & central area \\
\hline & 9 & Point & Skye bank & 246195 & 134643 & 1 & J B Yakubu road & Canteen area \\
\hline & 10 & Point & Fin bank & 246248 & 134637 & 1 & J B Yakubu road & Canteen area \\
\hline 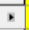 & 11 & Point & $U B A$ & 246038 & 134652 & 2 & J B Yakubu road & Canteen area \\
\hline & 12 & Point & unity bank 1 & 246351 & 134633 & 2 & J B Yakubu road & Canteen area \\
\hline & 13 & Point & union bank & 246379 & 134631 & 1 & J B Yakubu road & Canteen area \\
\hline & 14 & Point & unity bank 2 & 246480 & 134617 & 1 & J B Yakubu road & Canteen area \\
\hline & 15 & Point & bank phb & 245959 & 134690 & 2 & umaru musa yaradua way & central area \\
\hline & 16 & Point & diamond bank & 246307 & 134670 & 2 & sani abacha way & Tudun wada \\
\hline & 17 & Point & FCMB & 246342 & 134670 & 2 & sani abacha way & Tudun wada \\
\hline & 18 & Point & oceanic bank & 246362 & 134666 & 2 & sani abacha way & Tudun wada \\
\hline & 20 & Point & Stanbic IBTC & 246498 & 134655 & 1 & sani abacha way & Tudun wada \\
\hline
\end{tabular}

Figure 10: Attributes of all the ATM machines in Gusau metropolis 


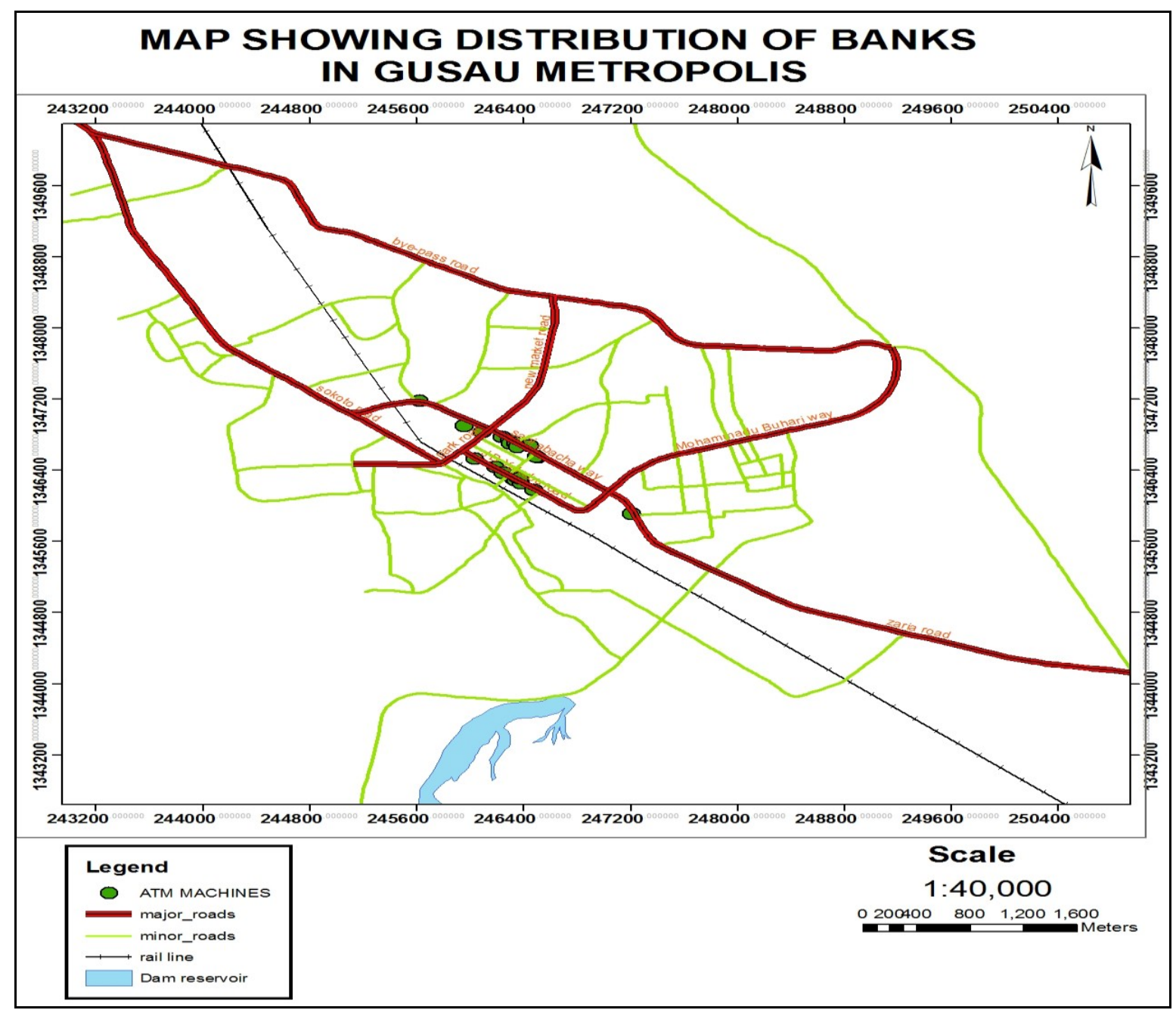

Figure 11: Distribution of ATM machines in Gusau metropolis

\section{Analysis}

From figure $3-11$, it is observed that there are 21 banks in the area of study. Also, there are 8 securities and fire services agencies evenly distributed within the metropolis. The results show clearly that there are more banks on Sani Abacha way and J B Yakubu road with 8 and 9 banks respectively as shown in Table 1. It can also be seen from the distributions that the banks have very high security as they are located near the central police station; the fire services are also very close to the area where the banks are located. On the other hand, majority of the banks have 2 ATMs within the banking area.

Table 1: Percentage of banks on major roads

\begin{tabular}{|l|c|c|c|}
\hline ROAD & NO OF BANKS & NO OF ATMs & PERCENTAGE \\
\hline Sani Abacha way & 8 & 12 & 38.0 \\
\hline J B yakubu road & 9 & 14 & 42.8 \\
\hline Park road & 1 & 3 & 4.8 \\
\hline Zaria road & 1 & 1 & 4.8 \\
\hline Umaru Musa Yaradua way & 2 & 3 & 9.6 \\
\hline
\end{tabular}

\section{Conclusions}

The report shows evidently the extent to which GIS aids in providing geographically referenced data necessary for inventory and monitoring of development process. This study also exposes the competition involved in the banking sector to capture and control market and business by residing very close to their clients with the sole interest of maximizing profit, by exploiting every business and market elements at their disposal. Although the banks well located, there is lack of even distribution of ATM machines within the metropolis which makes customers residing in extreme ends waste time and fuel in getting access to cash. 


\section{Recommendation}

ATMs are meant to ease the problems of bank transactions, thus ATMs should be made available and evenly distributed all over the metropolis, and these ATM stations should be open to the public for $24 \mathrm{hrs}$.

\section{References}

[1]. Kolawole, S. G. (2007). Basic Principles in Surveying. Lagos: Ganikol Publishers.

[2]. Kimerling, J.A. (1994). Geographic Information System and Cartography. Proceeding of a Seminar on Teaching Conventional and Digital Map production Lines, held at Istanbul technical University - Istanbul, Turkey, April, pp 35-45.

[3]. Escobar, F. and Hunter, G. (2006). Introduction to Geographical Information System. Department of Geomatics, the University of Melbourne. Retrieved from http://www.sli.unimelb.edu.au/gisweb/. Accessed on 12-09-2010.

[4]. Merri, P.(2009). Mapping Issues. Retrived from http://www.aud.edu. Accessed on 10-09-2010.

[5]. Garner, B.J. (2006) Developing GIS tools to Integrate MCDM models for the analysis of bank branches closure. The University of New South Wales. Retrieved from http://www.unsw .edu.au. Accessed on 13-09-2010.

[6]. Wikipedia (2010a). Database model. Retrieved from http://en.wikipedia.org/wiki/database model. Accessed on 10-09-2010.

[7]. Kufoniyi, G.O. (1998). Surveying and Information Technology. A paper Presented at Quarterly Luncheon Lecture Series of NIS, Lagos State Branch. $28^{\text {th }}$ September.

[8]. Wikipedia (2010b). Geographical Information System. Retrieved from http://en.wikipedia. org/wiki/geographical information system. Accessed on 10-09-2010

\section{Appendix: $\quad$ Final Map}

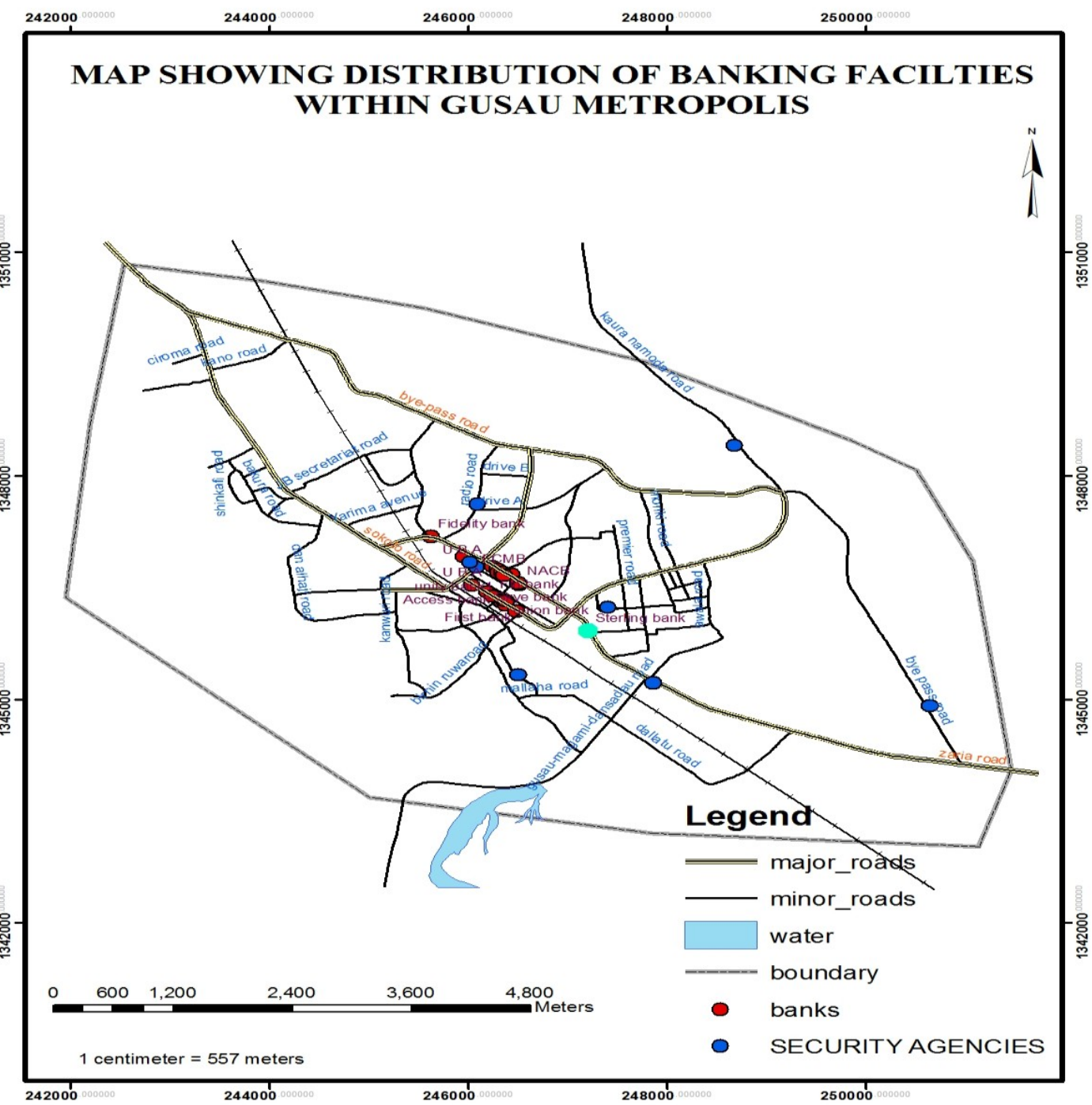

Figure 12: Distribution of Banks Facilities and Security Agencies within Gusau Metropolis 